Санкт-Петербургский клинический научно-практический центр специализированных видов медищинской помощи (онкологический) (Санкт-Петербург, Россия)

ИСПОЛЬЗОВАНИЕ БЛОКИРУЮЩЕГО КРИОЗОНДА ДЛЯ ИСКЛЮЧЕНИЯ ТЕПЛОВОЗВРАТА ОТ КРУПНОГО (D=10 ММ) СОСУДА ПРИ ПРОВЕДЕНИИ ЧРЕСКОЖНОЙ КРИОАБЛЯЦИИ METAСТАЗА В ПЕЧЕНИ

П.В. Балахнин, А.С. Шмелев, Е.Г. Шачинов, В.И. Малькевич, А.А. Мелдо, В.В. Егоренков, В.М. Моисеенко

\title{
USE OF BLOCKING CRYOPROBE FOR EXCEPTION OF HEAT RETURN FROM LARGE ( $D=10$ MM) VESSEL DURING PERCUTANEOUS CRYOABLATION OF LIVER METASTASIS
}

П.В. Балахнин

Кандидат медицинских наук, врач-хирург, стариий научный сотрудник научного отдела, заведуюший ОРХМДил,

Санкт-Петербургский клинический научно-практический центр специализированных видов медичинской помощи (онкологический),

197758, Россия, Санкт-Петербург, пос. Песочный, ул. Ленинградская, 68 .

E-mail: balabnin_p@mail.ru.

А.С. Шмелев Врач-хирург ОРХМДиЛ.

Е.Г. Шачинов

Научный сотрудник научного отдела, врач-хирург ОРХМДиЛ.

В.И. Малькевич Врач-онколог ОРХМДиЛ.

А.А. Мелдо

Кандидатмедицинских наук, заведуюшая отделением лучевой диагностики.

B.В. Егоренков

Кандидатмедицинских наук, заместитель директора по медицинской части (хирургической помощи).

В.М. Моисеенко

Доктор медицинских наук, профессор, директор.
P.V. Balakbnin

Candidate of Medicine, Surgeon, Senior Researcher of Scientific Department, Head of Department of Interventional Radiology.

St. Petersburg Clinical Research Center of specialized types of care (Oncology), 197758, Russia, St. Petersburg, Leningradskaya st. $68 \mathrm{~A}$ E-mail: balabnin_p@mail.ru.

A.S. Shmelev Surgeon,

Department of Interventional Radiology.

E.G. Shachinov

Researcher of Scientific Department, Surgeon of Department of Interventional Radiology.

V.I. Malkevich Clinical oncologist, Department of Interventional Radiology.

A.A. Meldo

Candidate of Medicine, Head of Department of Diagnostic Imaging.

V.V. Egorenkov Candidate of Medicine, Deputy Director of the Medical Unit

(Surgical Care).

V.M. Moiseyenko Doctor of Medicine, Professor, Director.

Актуальность. Существенным недостатком чрескожной криоабляции (ЧК) является ее низкая эффективность при лечении злокачественных опухолей печени, прилежащих к крупным (диаметром более 3 мм) кровеносным сосудам. Перенос тепла от крови к опухоли не позволяет создавать летальную гипотермию вблизи стенки крупного сосуда, что приводит к неполному некрозу патологической ткани или формированию недостаточного минимального края абляции (протяженностью менее 5 мм), чреватого локальным прогрессированием. В связи с 
этим целесообразность выполнения ЧК первичных и метастатических опухолей печени прилежащих к крупным сосудам ставится под сомнение.

Цель. Продемонстрировать случай технически успешной ЧК метастаза колоректального рака в печени, прилежащего к крупному (d=10 мм) сосуду, с использованием дополнительного, временно блокирующего кровоток в этом сосуде, криозонда - блокирующего криозонда.

Клиническое наблюдение. Пациентка М 73 лет обратилась в Онкоцентр по поводу впервые выявленного метахронного солитарного нерезектабельного (в связи с сопутствующей патологией) метастаза колоректального рака в печени диаметром 25 мм, локализованного в IVA сегменте и тесно прилежащего к крупному сосуду - средней печёночной вене (СПВ) диаметром 10 мм. Мультидисциплинарной комиссией принято решение выполнить ЧК метастаза под местной анестезией. Для временного прекращения кровотока по СПВ (с целью исключения тепловозврата к опухоли) во время проведения ЧК было решено установить дополнительный криозонд в непосредственной близости от СПВ (блокирующий криозонд) под контролем УЗИ и ПДКТ-артериогепатикографии. Установка блокирующего криозонда позволила сформировать «ледяной шар» в просвете СПВ и полностью прекратить кровоток по этому сосуду на время проведения ЧК. Благодаря этому был исключен эффект тепловозврата к опухоли и создана зона абляции необходимого размера, в результате чего процедура ЧК оказалась технически эффективной. После окончания ЧК отмечено полное восстановление кровотока по СПВ и ее ветвям, при этом осложнений после вмешательства не наблюдали.

Заключение. Применение одного или нескольких блокирующих криозондов может повысить техническую эффективность ЧК опухолей печени, тесно прилежащих к крупным сосудам, улучшить отдаленные результаты лечения подобных опухолей и расширить показания к применению ЧК опухолей печени в будущем.

Ключевые слова: аблячия, чрескожная криоаблящия, блокирующий криозонд, плоскодетекторная колпьютерная томография, капиллярная фаза артериогепатикографии, перитуморальное кольцевое контрастирование, ПдкТ.

Background. A significant shortcoming of percutaneous cryoablation (PC) is its low efficiency of the treatment of malignant liver tumors adjacent to large (more than $3 \mathrm{~mm}$ ) blood vessels. The transfer of heat from the blood to the tumor does not allow the creation of lethal hypothermia near the wall of a large vessel. This leads to incomplete necrosis of pathological tissue or the formation of an insufficient minimal ablation margin (less than $5 \mathrm{~mm}$ ), fraught with local progression. In this regard, the feasibility of performing the PC of primary and metastatic liver tumors adjacent to large vessels is being questioned.

Aim. To demonstrate the case of a technically successful PC of colorectal liver metastasis adjacent to the large (d=10 $\mathrm{mm}$ ) vessel using an additional cryoprobe which temporarily blocks the blood flow in this vessel (blocking cryoprobe).

Case presentation. The patient M 73 years old hospitalized in our clinic for the treatment of newly diagnosed metachronous solitary unresectable (in connection with concomitant diseases) colorectal liver metastasis $25 \mathrm{~mm}$ in diameter, localized in the IVA segment and closely adjacent to a large vessel - the middle hepatic vein (MHV) $10 \mathrm{~mm}$ in diameter. The multidisciplinary team was decided to carry out the PC of this metastasis under the local anesthesia. For the temporary cessation of blood flow over the MHV (in order to exclude heat transfer to the tumor) during the PC, it was decided to positioning an additional cryoprobe in the immediate vicinity of the MHV (blocking cryoprobe) under the US and FDCT during hepatic arteriography. The insertion of blocking cryoprobe allowed to create «ice ball» in the lumen of the MHV and completely block the blood flow in this vessel during PC. Due to this, the effect of heat return to the tumor was excluded and an ablation zone of the required volume was created. As a result, the procedure of PC was technically effective. After PC a complete recovery of blood flow through the MHV and its branches was noted, with no complications after the intervention.

Conclusion. The use of one or more blocking cryoprobes can increase the technical efficiency of PC of liver tumors closely adjacent to the large blood vessels, improve the long-term results of treatment of such tumors, and extend the indications for the PC of liver tumors in the future.

Keywords: ablation, percutaneous cryoablation, blocking cryoprobe, flat-detector computed tomography, capillary phase of hepatic arteriography, peritumoral ring enbancement, FDCT.

\section{Введение}

Ч рескожная криоабляция (ЧК) - это новый перспективный метод лечения нерезектабельных олигометастазов колоректального рака в печени, рекомендованный ЕSMO (наряду с РЧА и МВА) для широкого клинического использования. Однако, существенным недостатком ЧК (как и РЧА) является зависимость результатов лечения от эффекта тепловозврата (теплопотери при РЧА), проявляющаяся в сложности выполнения полной абляции опухолей в месте прилежания их к крупным (диаметром более 3 мм) кровеносным сосудам $[1,2]$. Интенсивный перенос тепла от крови к опухоли часто не позволяет создавать летальную гипотермию $\left(-20^{\circ} \mathrm{C}\right.$ и ниже) вблизи стенки крупного сосуда, в результате чего после выполнения процедуры абляции может сохраняться остаточная неаблированная опухоль (при этом ЧК считается фактически не выполненной) или формироваться недостаточный минимальный край аблящии протяженностью менее 5 мм. В этом случае абляция также считается технически не эффективной 
и сопровождается высоким риском локального прогрессирования заболевания - повторного появления опухоли в зоне выполненной процедуры [3]. Известно, что после чрескожной РЧА опухолей прилежащих к крупным кровеносным сосудам локальное прогрессирование наблюдается в 7 раз чаще, чем после абляции новообразований, расположенных вдали от сосудистых структур (48\% против 7\%), и это крайне негативно сказывается на отдаленных результатах лечения [3]. Поэтому при проведении РЧА и ЧК первичных и метастатических опухолей печени прилежащих к крупным сосудам рекомендуется применять дополнительные технические приемы, направленные на временное блокирование кровотока по целевым сосудам с целью прекращения теплопотери (тепловозврата при ЧК) $[1,2]$. Для этого, как правило, используют две рентгенохирургические методики - эмболизацию сосудов гемостатической губкой (для ветвей печёночной артерии и воротной вены) и баллонную окклюзию сосудов (для ветвей воротной вены и печеночных вен) [3, 4]. Однако использование данных методик в практическом здравоохранении крайне ограничено в связи с техническими сложностями, побочными әффектами и неоднозначными результатами [3].

В то же время ЧК обладает рядом уникальных преимуществ по сравнению с РЧА и МВА которые, теоретически, могут способствовать улучшению результатов лечения данной категории опухолей [5-8]. Во-первых, ЧК осуществляется под местной анестезией (без наркоза), давая возможность во время вмешательства выполнять все виды рентгенологических исследований при задержке дыхания пациента, что обеспечивает получение качественных изображений без наслоения «артефактов движения». Во-вторых, во время ЧК возможна постоянная визуализация «ледяного шара» как с помощью УЗИ, так и с помощью различных КТ-технологий, что позволяет с высокой степенью надежности осуществлять.мониторинг процедуры. В-третьих, во время ЧК существует возможность одновременного подключения до 25 криозондов (при РЧА только поочередное включение трех электродов, при МВА - двух антенн), что дает возможность часть из них использовать для вспомогательных манипуляций (например, для «приклеивания» тканей с целью их фиксации или тракции) [5-8]. Эти преимущества делают ЧК намного более прецизионной и технологичной процедурой по сравнению с РЧА и МВА, позволяя в полной мере использовать современные возможности визуализации, навигации, мониторинга, модификации в процессе абляции и оценки непосредственного ответа на лечение [9]. При этом, теоретически, часть криозондов может использоваться не для абляции опухоли, а для «промораживания» крупных сосудов с целью временного блокирования в них кровотока и, следовательно, предотвращения эффекта тепловозврата. Однако в доступной нам литературе мы не нашли описания случаев целенаправленного применения криозондов для блокирования кровотока по крупным кровеносным сосудам в процессе ЧК.

Цель клинического наблюдения - продемонстрировать случай технически успешной ЧК метастаза колоректального рака в печени, прилежащего к крупному (d=10 мм) сосуду, с использованием дополнительного, временно блокирующего кровоток в этом сосуде, криозонда - блокирующего криозонда.

\section{Клиническое наблюдение}

Пациентка М 73 лет в июле 2018 г. обратилась в Санкт-Петербургский Онкоцентр с диагнозом: $3 \mathrm{HO}$ сигмовидной кишки $\mathrm{p}_{1} \mathrm{~N}_{1} \mathrm{M}_{0}$, состояние после резекции сигмовидной кишки в августе 2017 г., состояние после 12 циклов адъювантной ПХТ по схеме FolFox, прогрессирование в июле 2018 г. в виде появления солитарного метастаза в печени; гемангиома правой доли печени (рис. 1А). При комплексном обследовании данных за рецидив заболевания в кишечнике и наличие метастазов в других органах не получено. Пациентка была обсуждена на мультидисциплинарной комиссии и, с учетом выраженной сопутствующей патологии (постинфарктный кардиосклероз, снижение фракции выброса ниже 50\%), для лечения опухоли решено было использовать один из видов чрескожной энергетической абляции. В отделении рентгенохирургии с целью дифференциальной диагностики образований печени и исключения дополнительных более мелких метастазов выполнена диагностическая плоскодетекторная компьютерная томография (ПДКТ) в капиллярную фазу инфузионной артериогепатикографии (ПДКТ-КФИАГ) по описанной ранее методике [9]. Для этого в артериальный катетер, установленный в общей печеночной артерии, вводили 40 мл неразведенного контрастного препарата Ультравист-370 со скоростью 2 мл/сек (продолжительность введения 20 сек) и выполняли сканирование (ротационную рентгенографию) печени на 22 сек от начала введения контрастного препарата (то есть через 2 сек после окончания контрастирования). Сканирование выполняли на ангиографической установке Artis Zee Floor (Siemens, Германия) в течение 6,6 сек в режиме DynaCT 8sDCT Body со скоростью вращения гентри $30^{\circ}$ в сек и частотой рентгенографии 60 кадров в сек. При анализе полученных томограмм было подтверждено наличие солитарного метастаза диаметром 25 мм в IVA сегменте печени и гемангиомы диаметром 11 мм в VII сегменте (рис. 1Б). Также было установлено, что метастатический узел тесно прилежит к крупным сосудам - средней печеночной вене (СПВ) диаметром 10 мм (рис. 1Б) и к ее более мелким ветвям, огибающим новообразование (рис. 1B). В связи с выраженной сопутствующей патологией от проведения МВА под общим наркозом решено было отказаться. Поэтому с целью лечения опухоли запланировали выполнить ангиографически-ассистированную ПДКТ-контролируемую ЧК подместной 
анестезией по описанной ранее методике $[9,10]$. На проведение вмешательства от пациентки было получено добровольное письменное информированное согласие. С целью создания адекватной зоны абляции (диаметр метастаза (25 мм) + минимальный край абляции $(10$ мм + 10 мм $)$ минимальная зона абляции (45 мм)) решено было одновременно использовать три криозонда IсеEDGE 2,4 ми (Galil Medical, CША), каждый из которых способен создавать «ледяной шар» (ледяной эллипсоид) с изотермой $-20^{\circ} \mathrm{C}$ размерами 30х48 мм (рис. 1Г). Таким образом, расчётные размеpы «ледяного шара» с изотермой $-20^{\circ} \mathrm{C}$ при использовании трех криозондов составили 58х56x48 мм. Однако кроме этих трех криозондов, для исключения эффекта тепловозврата, между СПВ и опухолевым узлом, в непосредственной близости от СПВ, решено было установить дополнительный аналогичный криозонд IceEDGE диаметром 2,4 мм. Целью установки этого криозонда являлось создание в просвете СПВ дополнительного «ледяного шара», блокирующего кровоток по СПВ в месте прилежания ее к опухоли. Поэтому данный криозонд решено было назвать блокируюшим криозондом. Расположение метастаза в

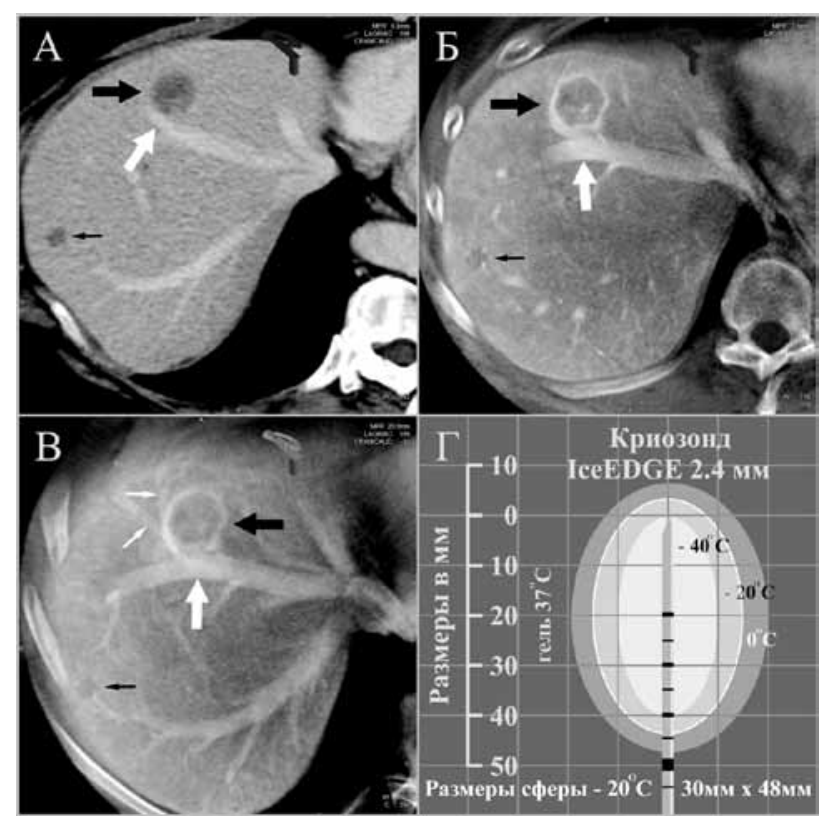

Рис. 1. Первичная и уточняющая диагностика очаговых образований печени и выбор криозондов для ЧК:

А) При МСКТ на догоспитальном этапе выявлено два патологических образования - гемангиома в S VI диаметром 11 ми (тонкая черная стрелка) и метастаз в S IVA диаметром 25 ми (толстая черная стрелка);

Б) ПДКТ-КФИАГ через 6 дней после МСКТ - подтверждена гемангиома (патогномоничный признак - лакуны) $u$ солитарный метастаз (патогномоничный признак перитуморальное кольцевое контрастирование);

В) Метастаз тесно прилежит к средней печеночной вене диаметром 10 ми (толстая белая стрелка) и ее ветвям (тонкие белые стрелки); Г) Размеры "ледяных сфер» генерируемых криозондом IсеEDGE диаметрам 2,4 ми (Galil Medical, США) в геле $37^{\circ} \mathrm{C}$ по данным фирмыпроизводителя.

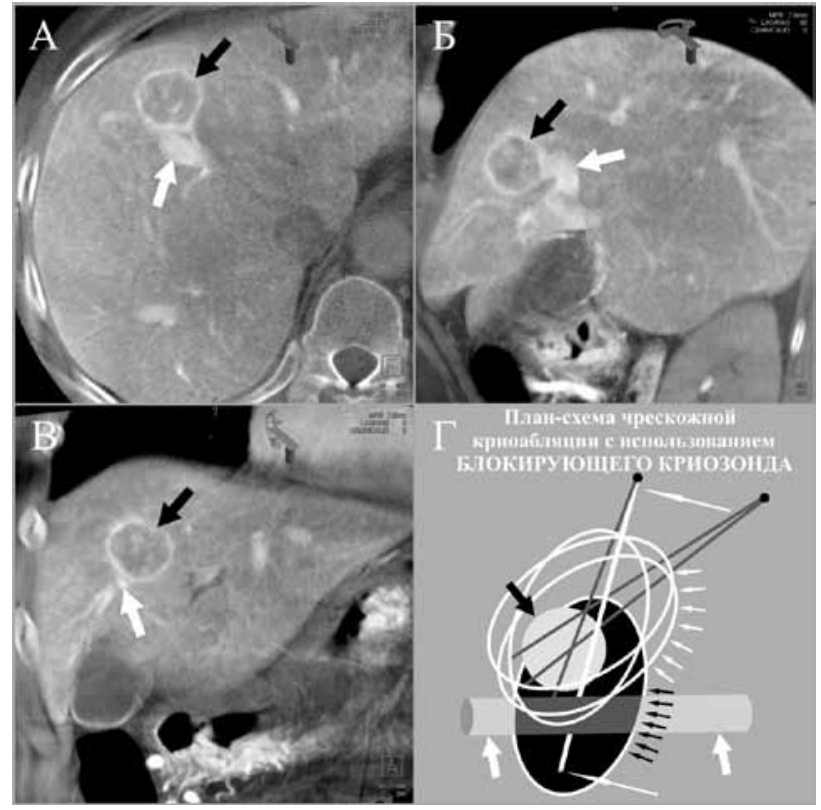

Рис. 2. Уточняюшая диагностика и планирование процедуры ЧК: А-В) Визуализащия метастаза при ПДКТ-КФИАГ обусловлена накоплением контрастного препарата в зоне его перитуморального кольцевого контрастирования

(толстые черные стрелки); опухоль тесно прилежит

$\kappa$ средней печеночной вене (СПВ) диаметром 10 мл и ее крупным ветвям (толстые белые стрелки); Г) Схема ЧК: три криозонда установлены в опухолевый узел (толстая черная стрелка) для формирования вокруг него «ледяного шара» $c$ температурой - $20^{\circ} \mathrm{C}$ (тонкие белье стрелки);

один блокирующий криозонд (длинные белые стрелки) установлен для прекращения кровотока по СПВ

(толстые белые стрелки) путем создания в ее просвете дополнительного «ледяного шара» (тонкие черные стрелки).

печени в трех проекциях по данным диагностической ПДКТ-КФИАГ представлено на рис. 2А-2В. Общая схема запланированной процедуры ЧК с использованием трех криозондов для аблящии и одного блокирующего криозонда для предотвращения тепловозврата от СПВ отражена на рис. 2Г.

Процедуру ангиографически-ассистированной ПДКТ-контролируемой ЧК выполнили через два дня после диагностической ПДКТ-КФИАГ в той же рентгеноперационной на ангиографической установке Artis Zee Floor по запланированной схеме и описанной ранее методике $[9,10]$. Для этого после катетеризации общей печеночной артерии и выполнения контрольного сканирования (ПДКТ-КФИАГ) под УЗИ-контролем в целевой опухолевый узел установили три криозонда IceEDGE 2,4 мм (Galil Medical, CША). После этого, также под контролем УЗИ, между опухолью и стенкой СПВ (в непосредственной близости от СПВ) установили дополнительный блокирующий криозонд. Для оценки положения криозондов выполнили контрольную ПДКТ без контрастирования. Полученный массив данных наложили на данные ПДКТ-КФИАГ с использованием программного пакета $3 D / 3 D$ Fusion (Siemens, Германия). При анализе полученных объединенных изображений положение всех четырех 
криозондов было расценено как адекватное (в соответствии с планом).

После этого был проведен пробный цикл замораживание опухоли на аппарате SeedNet Gold (Galil Medical, США) в течение 15 мин. в 100\% режиме подачи аргона. Сразу после окончания замораживания было выполнено контрольное сканирование в режиме ПДКТ-КФИАГ с целью одновременной оценки размеров и формы «ледяного шара» и получения информации о состоянии кровотока по печеночным венам. При анализе томограмм был выявлен остаточный кровоток в бассейне средней печёночной вены как проксимальнее «ледяного шара» (рис. 3А), так и непосредственно внутри него (рис. 3Б). Также было зафиксировано неравномерное формирование «ледяного шара» с очевидным дефектом контура в месте его соприкосновения со СПВ за счет эффекта тепловозврата (рис. 3Б). При этом было установлено, что кончик блокирующего криозонда расположен не совсем адекватно по сравнению с запланированным положением (более проксимально), что, по всей видимости, было связано с недостаточным его продвижением под ультразвуковым контролем в начале процедуры и неправильной оценкой положения при

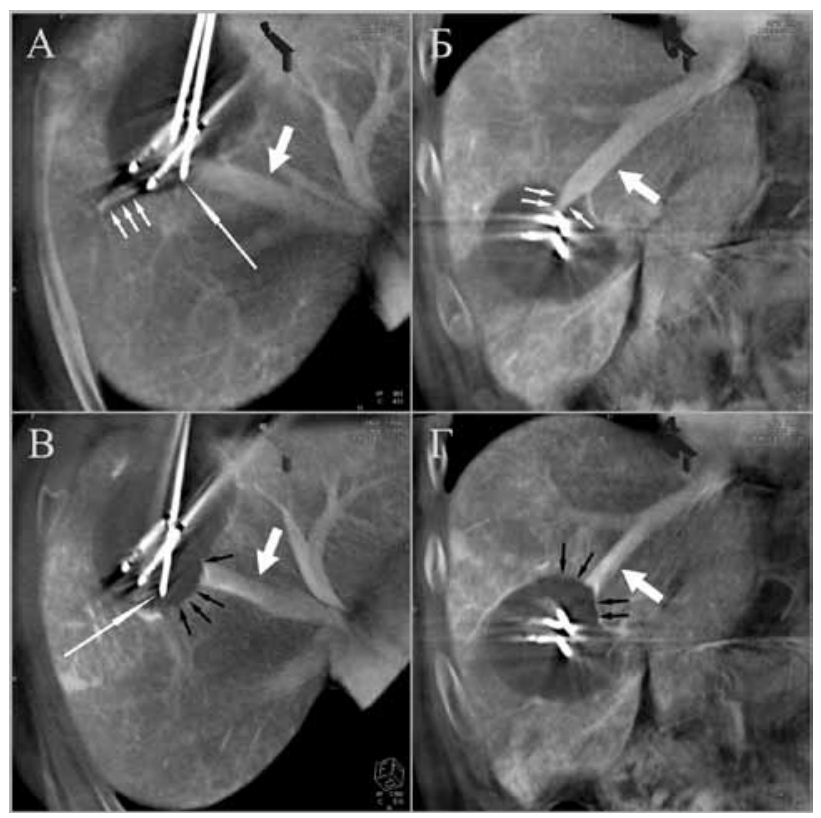

Рис. 3. Репозиционирование блокирующего криозонда с последующим полным прекращением кровотока по СПв на время ЧК: А, Б) ПДКТ-КФИАГ после «пробного» цикла замораживания: отмечается остаточный кровоток по проксимальным ветвям СПВ и стволу СПВ внутри «ледяного шара» (тонкие былые стрелки); выявлено неадекватное положение кончика блокирующего криозонда

(длинная белая стрелка); В, Г) Контрольная ПДКТ-КФИАГ после продвижения (репозиционирования) кончика блокирующего криозонда (длинная белая стрелка) $u$ повторного замораживания: кровотока по проксимальным ветвям СПВ и стволу СПВ внутри «ледяного шара» не определяется; визуализируется дополнительный контур «ледянго шара» от блокирующего криозонда в просвете СПВ (тонкие черные стрелки). контроле в режиме 3D/ 3D Fusion. В связи с этим после полного оттаивания ледяного шара (в течение 20 мин.) под контролем рентгеноскопии в режиме iGuide Needle Guidance (технология трехмерной навигащии в режиме реального времени) блокирующий криозонд был продвинут несколько дистальнее таким образом, чтобы центр его теплопоглощения (центр «ледяного шара») располагался непосредственно напротив центральной оси СПВ. После этого был осуществлен новый первый цикл заморажсивания опухоли в течение 15 мин. При очередном контрольном сканировании в прежнем режиме (ПДКТ-КФИАГ) по окончании этого цикла было выявлено полное отсутствие кровотока по СПВ как в проксимальных ее отделах, так и внутри «ледяного шара" (рис. 3В, рис. ЗГ). Обусловлено это было образованием льда непосредственно в просвете СПВ за счет установленного рядом с ней блокирующего криозонда, что было достоверно подтверждено полученными изображениями (рис. 3В, рис. 3Г). При этом форма «ледяного шара» в проекции опухоли стала сферической, а общие размеры его составили 72х59x 57 мм (рис. 4). С использованием режима 3D/ 3D Fusion было также подтверждено, что опухоль полностью перекрывается зоной абляции во всех проекциях не

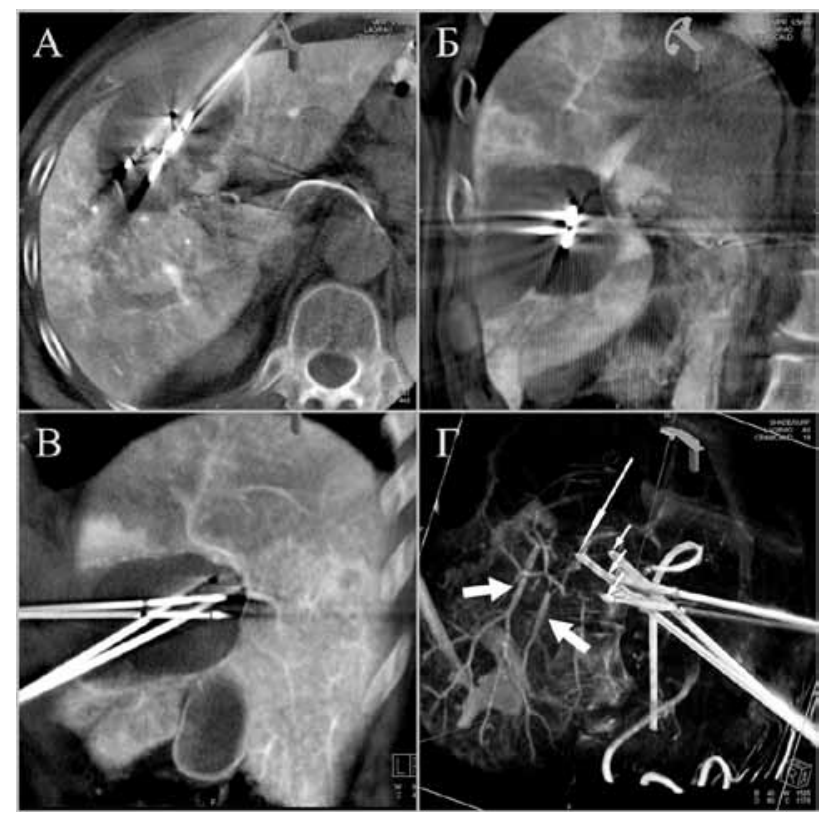

Рис. 4. Оченка размеров «ледяного шара» и положения криозондов после репозиционрования блокирующего криозонда и первого цикла повторного замораживания: $A-B)$ Визуализащия ледяного шара в трех проекциях контуры «ледяного шара» ровные, кровотока внутри «ледяного шара» не определяется; размеры «ледяного шара» составляют $72 x 59 \times 57$ мм.; Г) Визуализация положения криозондов в режиме $3 D$ - отчетливо видно положение трех криозондов, используемых для абляции метастаза (тонкие белые стрелки) и отдельно расположенного блокирующего криозонда (длинная белая стрелка); обращает на себя внимание контрастирование нескольких сегментарных печеночных вен (толстые белые стрелки) за счет нарушения оттока крови в бассейн блокированной СПВ. 


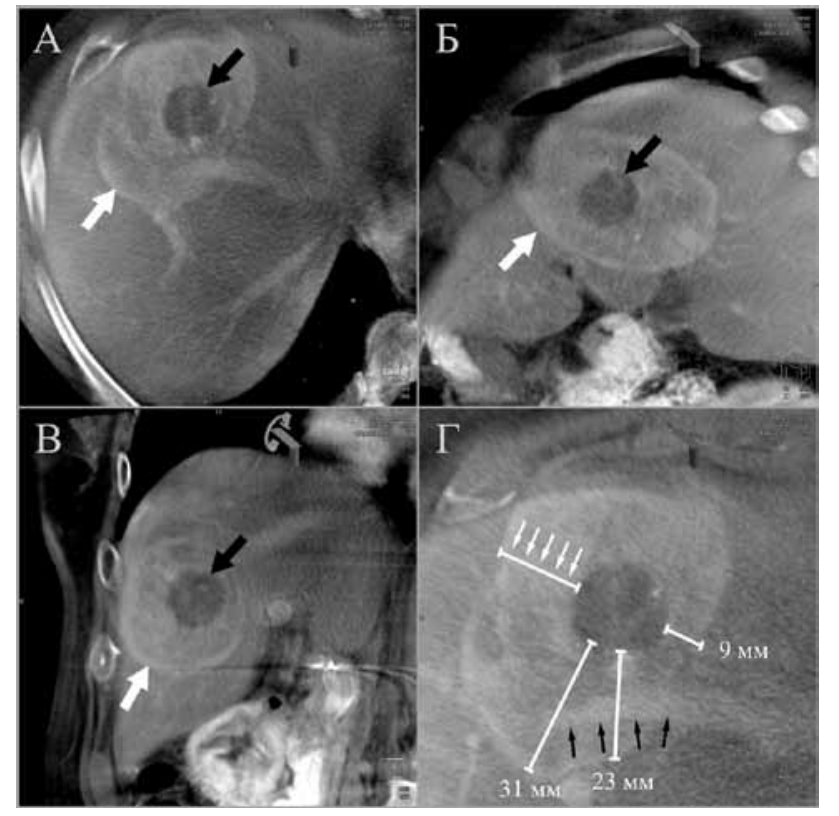

Рис. 5. Оченка непосредственного ответа на лечение по данным ПДКТ-ИФДАГ, выполненной сразу после ЧК: A-B) Визуализация аблированной опухоли (толстая черная стрелка) внутри сформированной зоны абляции (толстая белая стрелка) в трех проекция; Г) Увеличенное изображение зоны аблячии: тонкими бельми стрелками обозначен край аблящии - расстояние между краем опухоли и границей зоны абляции; хорошо видно, что минимальный край аблящии составляет 9 ми (процедура технически эффективна); отмечается восстановление кровотока по СПв (тонкие черные стрелки) подвергнутой замораживанию; СПВ проходит внутри края аблящии, что свидетельствует о том, что во время ЧК на формирование зоны абляции эффект тепловозврата не влиял в связи с отсутствием кровотока по СПв.

менее чем на 10 мм. В связи с этим положение криозондов было признано адекватным и после пассивного оттаивания опухоли (20 мин.) был осуществлен второй цикл замораживания в течение 15 мин.

После оттаивания «ледяного шара» и удаления всех четырех криозондов выполнена цифровая субтракционная ангиография для исключения кровотечения по пункционным каналам. С целью оценки размеров зоны абляции произведена контрольная ПДКТ в интерстищиальную фазу диффузионной артериогепатикографии (ПДКТ-ИФДАГ) по описанной ранее методике (введение 40 мл неразведенного контрастного препарата Ультравист-370 со скоростью 20 мл/мин. (продолжительность введения 120 сек), начало сканирования на 300 сек, то есть через 180 сек после окончания контрастирования) [9]. Как было показано ранее, методика ПДКТ-ИФДАГ дает возможность визуализировать не только всю зону абляции (гиперденсна по отношению к паренхиме печени), но и отдельно - аблированную опухолевую ткань в виде гиподенсного очагового образования (рис. 5) [9]. Благодаря этому при анализе полученных изображений было установлено, что размеры зоны абляции

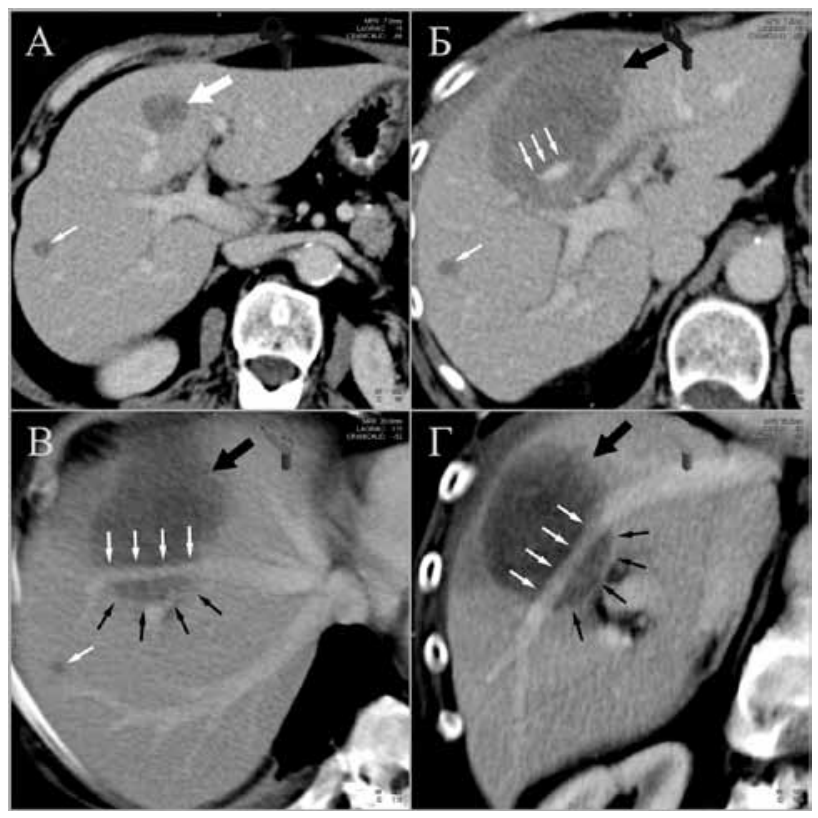

Рис. 6. Оченка ответа на лечение по данным МСКТ, выполненной через 20 часов после завершения ЧК:

А) Портальная фаза МСКТ за 8 дней до ЧК - определяется гемангиома (тонкая белая стрелка) и солитарный метастаз

(толстая белая стрелка); Б-Г) МСКТ после ЧК в трех проекциях - определяется зона абляции правильной формы (толстая черная стрелка), внутри которой проходит СПв с сохраненным по ней кровотоком (тонкие белые стрелки); данных за образование тромбов в просвете СПВ нет; В, Г) Зона аблящии правильной формы дистальнее СПВ (тонкие черные стрелки) свидетельствует о том,

что во время проведения ЧК кровоток по этой вене отсутствовал (благодаря установленному блокирующему криозонду) и эффект тепловозврата был полностью исключен.

составили 70х56x54 мм, а аблированный опухолевый узел полностью находится внутри этой зоны (рис. 5А-5В). Более того, раздельная визуализащия аблированной опухоли и зоны абляции дала возможность точно определить минимальный край аблящии, который составил 9 мм (рис. 5Г). Это позволило сделать вывод о том, что процедура ЧК была выполнена технически эффективно. Крайне важным оказался тот факт, что край абляции в области непосредственного прилежания опухоли к СПВ составил целых 23 мм (!!!) и полностью включал в себя этот крупный сосуд со значительным дополнительным аблированным запасом паренхимы (рис. 5Г). Это доказывало факт полного отсутствия кровотока по СПВ в процессе ЧК. При этом сразу после оттаивания «ледяного шара» (уже при ПДКТ-ИФДАГ) мы наблюдали полное восстановление кровотока по СПВ и ее ветвям (рис. 5Г).

Процедура ЧК на этом была завершена, а на следующие сутки (через 20 часов после абляции) произведена контрольная многофазная МСКТ (рис. 6). При анализе полученных томограмм было установлено следующее: 1) Зона абляции полностью перекрывает опухолевый очаг с соблюдением достаточного 
минимального края абляции, то есть процедура ЧК технически эффективна (рис. 6А vs рис. 6Б); 2) Зона абляции содержит в себе часть СПВ в месте прилежания ее к метастазу, а край зоны абляции в этом месте имеет правильную сферическую форму (рис. 6Б-6Г). Это еще раз косвенно подтвердило тот факт, что во время ЧК кровоток по СПВ был полностью блокирован и этот сосуд никак не влиял на равномерное формирование «ледяного шара» и зоны абляции; 3) После ЧК произошло полное восстановление кровотока по СПВ в месте ее промораживания и в послеоперационном периоде признаков тромбоза этого сосуда не возникло (рис. 6В, рис. 6Г).

Осложнений после вмешательства не наблюдали. Пациентка выписана из стационара на седьмые сутки после процедуры ЧК в удовлетворительном состоянии.

\section{Обсуждение}

Первая коммерчески доступная система для криодеструкиии опухолей, основанная на методе накачки жидкого азота, была создана в 1991 г., а в 1993 г. Onik G. et al. сообщили об успешном опыте ее клинического применения для лечения опухолей печени [8]. Однако диаметр используемых троакарных аппликаторов равнялся в то время 10-12 мм, поэтому проведение криодеструкции в клинической практике было возможным только открытым или лапароскопическим способом, то есть исключительно с использованием хирургических методов лечения. При этом роль рентгенохирургии при проведении криодеструкиии опухолей различных локализаций ограничивалась только выполнением эмболизации сосудов с целью снижения эффекта тепловозврата во время процесса замораживания [11].

Появление и стремительное развитие чрескожной криоаблящии связано с созданием в начале 2000-х гг. коммерчески доступных криогенных установок третьего поколения, в которых для охлаждения криозондов используется не жидкий азот, а находящийся под большим давлением газ аргон. Изменение технологии охлаждения криозондов (переход с жидкого теплоносителя на газообразный) позволило почти в десять раз уменьшить их диаметр (до 13-17 G, или 2,4-1,5 мм), что сделало возможным безопасное использование криоабляции в интервенционной радиологии (рентгенохирургии) [8]. Ранее нами была разработана методика ангиографически-ассистированной ПДКТконтролируемой ЧК первичных и метастатических опухолей печени, основанная на широком использовании внутриартериального контрастирования, позволяющего в полной мере использовать современные возможности визуализации, навигации, мониторинга, модификащии в процессе аблящии и оценки непосредственного ответа налечение [9]. Внедрению методики в практику предшествовал длительный опыт использования внутриартериального контрастирова- ния для других целей интервенционной радиологии, в том числе для диагностики мелких и очень мелких гиповаскулярных метастазов в печени [12-15]. В настоящее время использование внутриартериального контрастирования позволяет проводить тщательный мониторинг процесса аблящии, в том числе контролировать состояние различных сосудистых структур. Это позволило нам прецизионно изучить возможность применения одного или нескольких криозондов для временного блокирования кровотока по крупным сосудам, расположенным вблизи целевых опухолевых узлов.

Как было показано в данном клиническом наблюдении, установка дополнительного, блокирующего

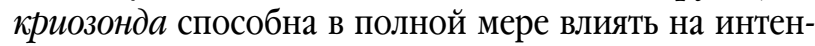
сивность кровотока в просвете целевого сосуда вплоть до его полного прекращения путем формирования внутрипросветного «ледяного шара». Это открывает новые возможности управления внутрипеченочным кровотоком при проведении ЧК. Учитывая, что во время ЧК одновременно может использоваться до 25 криозондов, а в процессе абляции одной опухоли задействовано не более 3-7 аппликаторов, остальные могут применяться для блокирования и перераспределения кровотока по крупным кровеносным сосудам (артериям, ветвям воротной вены и печеночным венам).

В эксперименте на свиньях Eggstein S. et al. показали, что даже полное замораживание ствола нижней полой вены не приводит к нарушению целостности этого сосуда, не влияет на эластические свойства коллагеновых волокон, входящих в состав его стенки и не способствует тромбообразованию в его просвете в послеоперационном периоде [16]. В клиническом исследовании Sainani N.I. et al. [17] после выполнения ЧК центрально расположенных опухолей печени, прилежащих к крупным сосудам, авторы также не наблюдали ни одного случая постабляционного тромбоза печеночных вен и ветвей воротной вены, диаметр которых превышал 4 мм. В то же время авторы отмечали, что тромбоз мелких венозных ветвей (диаметром менее 4 мм) при ЧК периферических опухолей наблюдался у каждого четвертого пациента, но при этом ни в одном наблюдении он не имел негативных клинических последствий, не носил прогрессирующего характера и спонтанно исчезал с течением времени. В связи с этим авторы сделали вывод о том, что промораживание как мелких, так и крупных сосудов печени во время ЧК является безопасной и допустимой процедурой [17]. В нашем клиническом наблюдении мы также наблюдали, что целенаправленное создание «ледяного шара» в просвете крупного сосуда (то есть его полное промораживание) не повлекло за собой негативных последствий и сопровождалось полным восстановлением кровотока в его просвете после окончания процесса криоабляции.

Перспективным для проведения ангиографически-ассистированной ПДКТ-контролируемой ЧК 
представляется использование длительного (хронического) артериального доступа, который может быть обеспечен путем имплантации внутриартериальных систем порт-катетер. Такие системы могут имплантироваться в печеночную артерию как хирургически, так и чрескожно - с применением рентгенохирургических технологий $[18,19]$. Наличие имплантированной внутриартериальной системы порт-катетер даст возможность осуществлять конверсионную внутриартериальную химиотерапию потенииально-курабельных метастазов, направленную на уменьшение их размеров до размеров, подходящих для выполнения ЧК. При этом применение описанной нами методики блокирующих криозондов (на фоне внутриартериального контрастирования через порт) может обеспечить адекватную ЧК опухолей, прилежащих к крупным сосудам без использования дополнительного артериального доступа и вспомогательных технологий в виде эмболизации или баллонной окклюзии. Постоянный артериальный доступ позволит также проводить качественный мониторинг за процессом ЧК при выполнении многоэтапных процедур, направленных на лечение множественных опухолей. После проведения ЧК артериальный порт может быть использован для адъювантной регионарной химиотерапии, а также для динамического наблюдения за пациентами группы высокого риска с целью ранней диагностики локального рецидива или локального прогрессирования заболевания [9].

\section{Заключение}

Поскольку методика ЧК практически не ограничивает число используемых аппликаторов (до 25 единиц одновременно), в процессе проведения процедуры могут использоваться дополнительные криозонды, установка которых направлена не на абляцию опухоли, а на блокирование кровотока по крупным сосудам путем формирования в их просвете «ледяного шара». Такие криозонды мы предлагаем называть блокирующими. В данном клиническом наблюдении при проведении ЧК метастаза тесно прилежащего к крупному кровеносному сосуду диаметром 10 мм применение блокирующего криозонда позволило полностью прекратить кровоток по этому сосуду на время выполнения процедуры, исключить эффект тепловозврата и тем самым обеспечить формирование адекватного края абляции. Таким образом, применение блокирующих криозондов может повысить техническую эффективность ЧК опухолей, тесно прилежащих к сосудам диаметром более 3 мм, улучшить отдаленные результаты лечения подобных опухолей, а также расширить показания к применению ЧК в будущем. Необходимо проведение дальнейших исследований, направленных на изучение технической и клинической эффективности применения методики блокирующих криозондов при выполнении ЧК первичных и метастатических опухолей печени, прилежащих к крупным сосудам.

\section{Список литературы}

1. Abmed M., Solbiati L., Brace C.L., Breen D.J., Callstrom M.R., Charboneau J.W., Chen M.H., Choi B.I., de Baère T., Dodd G.D. 3rd, Dupuy D.E., Gervais D.A., Gianfelice D., Gillams A.R., Lee F.T. Jr, Leen E., Lencioni R., Littrup P.J., Livraghi T., Lu D.S., McGahan J.P., Meloni M.F., Nikolic B., Pereira P.L., Liang P., Rhim H., Rose S.C., Salem R., Sofocleous C.T., Solomon S.B., Soulen M.C., Tanaka M., Vogl T.J., Wood B.J., Goldberg S.N.; International Working Group on Image-Guided Tumor Ablation; Interventional Oncology Sans Frontières Expert Panel; Technology Assessment Committee of the Society of Interventional Radiology; Standard of Practice Committee of the Cardiovascular and Interventional Radiological Society of Europe. Image-guided tumor ablation: standardization of terminology and reporting criteria - a 10-year update // J Vasc Interv Radiol. - 2014. - Vol. 25, № 11. - P. 1691-705. e4.

2. Miyazaki M., Iguchi T., Takaki H., Yamanaka T., Tamura Y., Tokue H., Sato Y., Ikeda O., Shimizu T., Yamakado K. Ablation protocols and ancillary procedures in tumor ablation therapy: consensus from Japanese experts // Jpn J Radiol. - 2016. - Vol. 34, № 9. - P. 647-56.

3. Mann C.D., Metcalfe M.S., Lloyd D.M., Maddern G.J., Dennison A.R. The safety and efficacy of ablative techniques adjacent to the hepatic vasculature and biliary system // ANZ J Surg. - 2010. - Vol. 80, № 1-2. - P. 41-9.

4. Kim J.W., Shin S.S., Heo S.H., Hong J.H., Lim H.S., Seon H.J., Hur Y.H., Park C.H., Jeong Y.Y., Kang H.K. UltrasoundGuided Percutaneous Radiofrequency Ablation of Liver Tumors: How We Do It Safely and Completely // Korean J Radiol. - 2015. - Vol. 16, № 6. - P. 1226-39.

5. Hinshaw J.L., Lubner M.G., Ziemlewicz T.J., Lee F.T. Jr, Brace C.L. Percutaneous tumor ablation tools: microwave, radiofrequency, or cryoablation - what should you use and why? // Radiographics. - 2014. - Vol. 34, № 5. - P. 1344-62.

6. Erinjeri J.P., Clark T.W. Cryoablation: mechanism of action and devices // J Vasc Interv Radiol. - 2010. - Vol. 21, Suppl 8. - P. 187-91.

7. Yılmaz S., Özdoğan M., Cevener M., Ozluk A., Kargi A., Kendiroglu F., Ogretmen I., Yildiz A. Use of cryoablation beyond the prostate // Insights Imaging. - 2016. - Vol. 7, № 2. - P. 223-32.

8. Балахнин П.В., Шмелев А.С., Шачинов Е.Г. Чрескожная энергетическая абляция опухолей: принципы, технологии, результаты // Практическая онкология. - 2016. - Т. 17, № 3. - С. 129-153. 
9. Балахнин П.В., Шачинов Е.Г., Шмелев А.С., Мелдо А.А., Цикоридзе М.Ю., Черниковский ИЛ., Егоренков В.В., Моисеенко В.М. Внутриартериальное контрастирование для визуализации, навигации, мониторинга и оценки ответа на леченое при проведении чрескожной криоабляции гиповаскулярных метастазов в печени // Практическая онкология. - 2018. - Т. 19, № 1. - С. 69-92.

10.Балахнин П.В., Шмелев А.С., Шачинов Е.Г., Мелдо А.А., Мацко Д.Е., Моисеенко В.М. Чрескожная криоабляция опухолей печени: Технические аспекты и непосредственные результаты // Русский медицинский журнал. 2017. - Т. 25, № 16. - С. 1206.

11. Манихас Г.М., Ханевич М.Д., Вашкуров С.М., Анисимова А.В., Фадеев Р.В., Балахнин П.В., Чалаев А.Г. Хирургическое лечение гигантских сарком мягких тканей // Саркомы костей, мягких тканей и опухоли кожи. - 2009. - № 1. - С. 62-67.

12. Балахнин П.В. Значение вариантов артериальной анатомии печени для выполнения интервенционнорадиологических вмешательств: автореф. дисс. ... канд. мед. наук. - Санкт-Петербург. - 2012. - 22 с.

13. Балахнин П.В., Манихас Г.М., Ханевич М.Д., Аносов Н.А., Фридман М.Х., Антимоник Н.Ю., Зорина Е.Ю., Фадеев Р.В., Юсифов С.А. Предварительные результаты применения плоскодетекторной компьютерной томографии на С-дуге на фоне капиллярной фазы артериогепатикографии (ПДКТ-АГ) для диагностики метастазов колоректального рака в печень // Диагностическая и интервенционная радиология. - 2010. T. 4, № 4. - C. 19-29.

14.Балахнин П.В., Поздняков А.В., Рылло А.Г., Шмелев А.С., Козырева К.С. Оптимальный метод контрастирования для диагностики мелких гиповаскулярных метастазов в печени во время МСКТ-артериогепатикографии // Российский онкологический журнал. - 2014. - Т. 19, № 4. - С. 18.

15. Балахнин П.В., Шмелев А.С., Шачинов Е.Г., Цикоридзе М.Ю., Поздняков А.В., Мацко Д.Е., Моисеенко B.M. Природа и перфузионная динамика перитуморального кольцевого контрастирования мелких (5-9 мм) и очень мелких (<5мм) гиповаскулярных метастазов в печени: анализ данных динамической КТ-артериогепатикографии // Практическая онкология. - 2017. - Т. 18, № S1. - С. 58-78.

16. Eggstein S., Neeff H., Szarzynski M., Jungraithmayr W., Haberstrob J., Kirste G., Schmitt-Graeff A., Farthmann E.H. Hepatic cryotherapy involving the vena cava. Experimental study in a pig liver model // Eur Surg Res. - 2003. Vol. 35, № 2. - P. 67-74.

17. Sainani N.I., Silverman S.G., Tuna I.S., Aghayev A., Shyn P.B., Tuncali K., Kadiyala V., Tatli S. Incidence and clinical sequelae of portal and hepatic venous thrombosis following percutaneous cryoablation of liver tumors // Abdom Radiol (NY). - 2016. - Vol. 41, № 5. - P. 970-7.

18. Балахнин П.В., Таразов П.Г., Поликарпов А.А., Суворова Ю.В., Козлов А.В. Длительная регионарная химиотерапия при метастазах колоректального рака в печень: значение артериальной анатомии для хирургической установки имплантируемых инфузионных систем // Вопросы онкологии. - 2003. - Т. 49, № 5. - С. 588-594.

19. Генералов М.И., Балахнин П.В., Руткин И.О., Полысалов В.Н., Таразов П.Г., Поликарпов А.А., Розенгауз Е.В., ИвановаА.А., Калашников П.А., Гранов Д.А. Внутриартериальная химиотерапия с использованием имплантируемых инфузионных систем в лечении пациентов с метастазами колоректального рака в печень // Вопросы онкологии. - 2007. - Т. 53, № 1. - С. 72-78.

\section{References}

1. Abmed M., Solbiati L., Brace C.L., Breen D.J., Callstrom M.R., Charboneau J.W., Chen M.H., Choi B.I., de Baère T., Dodd G.D. 3rd, Dupuy D.E., Gervais D.A., Gianfelice D., Gillams A.R., Lee F.T. Jr, Leen E., Lencioni R., Littrup P.J., Livraghi T., Lu D.S., McGaban J.P., Meloni M.F., Nikolic B., Pereira P.L., Liang P., Rhim H., Rose S.C., Salem R., Sofocleous C.T., Solomon S.B., Soulen M.C., Tanaka M., Vogl T.J., Wood B.J., Goldberg S.N.; International Working Group on ImageGuided Tumor Ablation; Interventional Oncology Sans Frontières Expert Panel; Technology Assessment Committee of the Society of Interventional Radiology; Standard of Practice Committee of the Cardiovascular and Interventional Radiological Society of Europe. Image-guided tumor ablation: standardization of terminology and reporting criteria - a 10-year update. J Vasc Interv Radiol. 2014 Nov; 25(11): 1691-705. e4. doi: 10.1016/j.jvir.2014.08.027.

2. Miyazaki M., Iguchi T., Takaki H., Yamanaka T., Tamura Y., Tokue H., Sato Y., Ikeda O., Shimizu T., Yamakado K. Ablation protocols and ancillary procedures in tumor ablation therapy: consensus from Japanese experts. Jpn J Radiol. 2016 Sep; 34(9): 647-56. doi: 10.1007/s11604-016-0569-8.

3. Mann C.D., Metcalfe M.S., Lloyd D.M., Maddern G.J., Dennison A.R. The safety and efficacy of ablative techniques adjacent to the hepatic vasculature and biliary system. ANZ J Surg. 2010 Jan; 80(1-2): 41-9. doi: 10.1111/j.14452197.2009.05174.x.

4. Kim J.W., Shin S.S., Heo S.H., Hong J.H., Lim H.S., Seon H.J., Hur Y.H., Park C.H., Jeong Y.Y., Kang H.K. UltrasoundGuided Percutaneous Radiofrequency Ablation of Liver Tumors: How We Do It Safely and Completely. Korean J Radiol. 2015 Nov-Dec; 16(6): 1226-39. doi: 10.3348/kjr.2015.16.6.1226.

5. Hinshaw J.L., Lubner M.G., Ziemlewicz T.J., Lee F.T.Jr, Brace C.L. Percutaneous tumor ablation tools: microwave, radiofrequency, or cryoablation - what should you use and why? Radiographics. 2014 Sep-Oct; 34(5): 1344-62. doi: $10.1148 / \mathrm{rg} .345140054$.

6. Erinjeri J.P., Clark T.W. Cryoablation: mechanism of action and devices. J Vasc Interv Radiol. 2010 Aug; 21(8 Suppl): 187-91. doi: 10.1016/j.jvir.2009.12.403. 
7. Yılmaz S., Özdoğan M., Cevener M., Ozluk A., Kargi A., Kendiroglu F., Ogretmen I., Yildiz A. Use of cryoablation beyond the prostate. Insights Imaging. $2016 \mathrm{Apr}$; 7(2): 223-32. doi: 10.1007/s13244-015-0460-7.

8. Balakhnin P.V., Shmelev A.S., Shachinov E.G. Percutaneous energy-based tumor ablation: principles, technologies, results. Prakticheskaja onkologija. 2016; 17(3): 129-153. (In Russ).

9. Balakhnin P.V., Shachinov E.G., Shmelev A.S., Meldo A.A., Tsikoridze M.J., Chernikovskiy I.L., Egorenkov V.V., Moiseyenko V.M. Intra-arterial contrast material injection for visualization, navigation, monitoring and assessment of treatment response during percutaneous cryoablation of hypovascular liver metastases. Prakticheskaja onkologija. 2018; 19(1): 69-92. (In Russ).

10. Balakbnin P.V., Shmelev A.S., Shachinov E.G., Meldo A.A., Matsko D.E., Moiseyenko V.M. Percutaneous cryoablation of liver tumors: Technical aspects and immediate results. Russian Medical Journal. 2017; 25(16): 1206. (In Russ).

11.Manikhas G.M., Khanevich M.D., Vashkurov S.M., Anisimova A.V., Fadeev R.V., Balakhnin P.V., ChalaevA.G. Surgical treatment of giant soft tissue sarcomas. Sarkomy kostej, mjagkih tkanej i opuholi kozhi. 2009; 1: 62-67. (In Russ).

12. Balakbnin P.V. The significance of variants of arterial anatomy of the liver for performing interventional and radiological interventions: abst. diss. cand of med. Saint Petersburg. 2012; 22. (In Russ).

13. Balakhnin P.V., Manikhas G.M., Khanevich M.D., Anosov N.A., Fridman M.H., Antimonik N.Ju., Zorina E.Ju., Fadeev R.V., Jusifov S.A. Preliminary results of flat-detector computed tomography using C-arm systems during capillary phase of infusion hepatic arteriography (FD-CT-A) in the detection and assessment of colorectal liver metastases. Diagnosticheskaja i intervencionnaja radiologija. 2010; 4(4): 19-29. (In Russ).

14. Balakbnin P.V., Pozdnyakov A.V., Ryllo A.G., Shmelev A.S., Kozyreva K.S. Optimal contrast study method for diagnoses of small hypovascular liver metastases during MSCT arterio-hepatography. Russian Journal of Oncology. 2014; 19(4): 18. (In Russ).

15.Balakhnin P.V., Shmelev A.S., Shachinov E.G., Tsikoridze M.J., PozdnyakovA.V., Matsko D.E., Moiseyenko V.M. Nature and perfusion dynamics of peritumoral ring enhancement of small $(5-9 \mathrm{~mm})$ and very small $(<5 \mathrm{~mm})$ hypovascular liver metastases: dynamic CT during hepatic arteriography data analysis. Prakticheskaja onkologija. 2017; 18(S1): 58-78. (In Russ).

16. Eggstein S., Neeff H., Szarzynski M., Jungraithmayr W., Haberstroh J., Kirste G., Schmitt-Graeff A., Farthmann E.H. Hepatic cryotherapy involving the vena cava. Experimental study in a pig liver model. Eur Surg Res. 2003 Mar-Apr; 35(2): 67-74.

17. Sainani N.I., Silverman S.G., Tuna I.S., Aghayev A., Shyn P.B., Tuncali K., Kadiyala V., Tatli S. Incidence and clinical sequelae of portal and hepatic venous thrombosis following percutaneous cryoablation of liver tumors. Abdom Radiol (NY). 2016 May; 41(5): 970-7. doi: 10.1007/s00261-015-0626-2.

18. Balakhnin P.V., Tarazov P.G., Polikarpov A.A., Suvorova J.V., Kozlov A.V. Long-term regional chemotherapy of colorectal liver metastasis: role of aberrant hepatic arterial anatomy identification in placement of implantable hepatic arterial infusion devices. Voprosy onkologii. 2003; 49(5): 588-594. (In Russ).

19. Generalov M.I., Balakhnin P.V., Rutkin I.O., Polysalov V.N., Tarazov P.G., Polykarpov A.A., Rosenhous Ye.V., Ivanova A.A., Kalashnikov P.A., Granov D.A. Intraarterial chemotherapy using implantable port-catheter system in patients with colorectal liver metastases. Voprosy onkologii. 2007; 53(1): 72-78. (In Russ). 